\title{
Simulation modeling of process parameters mixing dry mortar in the horizontal continuous mixer drum
}

\section{Wai Phyo Aung}

Republic of the Union of Myanmar, Postgraduate Student, Department of «Automated Control Systems».

Moscow Automobile \& Road construction State Technical University, 125319, Russian Federation, Moscow, Leningradsky prospekt, 64. Tel.: + 7 (499) 151-64-12. http://www.madi.ru

\section{myfamily46123@gmail.com}

\begin{abstract}
The article analyzes the method of optimizing the parameters of horizontal dry mixer. Developed functional and logical structure simulation model of a horizontal mixer. Briefly describes the process of mixing the dry mixtures. Achieved simulation of horizontal continuous mixer at medium AnyLogic, in order to optimize the process parameters of mixing dry mortars.
\end{abstract}

Keywords: horizontal mixer for dry mixes, AnyLogic, simulation, modeling, automated process and production, control software, automated control. 
ISSN 2306-1561

Автоматизация и управление в технических системах (АУТС) 2014. - №1.1(8). - C. 122-128.

DOI: $10.12731 / 2306-1561-2014-1-13$

\title{
УДК 681.3
}

\section{Имитационное моделирование параметров процесса смешивания сухих строительных смесей в горизонтальном барабанном смесителе непрерывного действия}

\author{
Вэй Пьо Аунг \\ Республика Союза Мьянма, аспирант кафедры «Автоматизированные системы управления». \\ ФГБОУ ВПО «Московский автомобильно-дорожный государственный технический \\ университет (МАДИ)», 125319, Российская Федерация, г. Москва, Ленинградский проспект, \\ д.64, Тел.: +7 (499) 151-64-12, http://www.madi.ru
}

myfamily46123@gmail.com

Аннотация. В статье анализируется метод оптимизации параметров в горизонтальном сухом смесителе. Разрабатываются функциональные и логические структуры имитационной модели работы горизонтального смесителя. Кратко описывается технологический процесс смешивания сухих смесей. Выполнено имитационное моделирование работы горизонтального смесителя непрерывного действия в среде AnyLogic, с целью оптимизации параметров процесса смешивания сухих строительных смесей.

Ключевые слова: горизонтальный смеситель для сухих смесей, AnyLogic, имитация, моделирование, автоматизированный процесс и производство, программное обеспечение для контроля, автоматизированное управление.

\section{1. Введение}

Сухие строительные смеси (ссс) - это приготовленные в заводских условиях, оптимизированные по составу смеси вяжущих веществ, заполнителей, наполнителей и функциональных добавок.

Развитие производства сухих смесей в мировой практике связано, прежде всего, с необходимостью увеличения производительности труда строителей при выполнении отделочных и специальных строительных работ и с повышением их качества, что определяется углублением специализации применяемых материалов. Для каждого вида 
строительных работ разработаны специальные виды растворных смесей, приготовление которых по традиционной «мокрой» технологии нерационально [1 - 5, 11 - 13].

\section{2. Классификация смесителей}

Дозированные материалы, поданные в смеситель, перемешиваются в соответствии с заданной программой. В программу работы смесителя для каждого рецепта закладываются время смешивания, возможность применения дополнительных миксеров, установленных в боковых стенках смесителя. Смешанная готовая продукция из смесителя подается в буферную емкость, откуда при помощи распределителя поступает на соответствующие линии упаковки и погрузки.

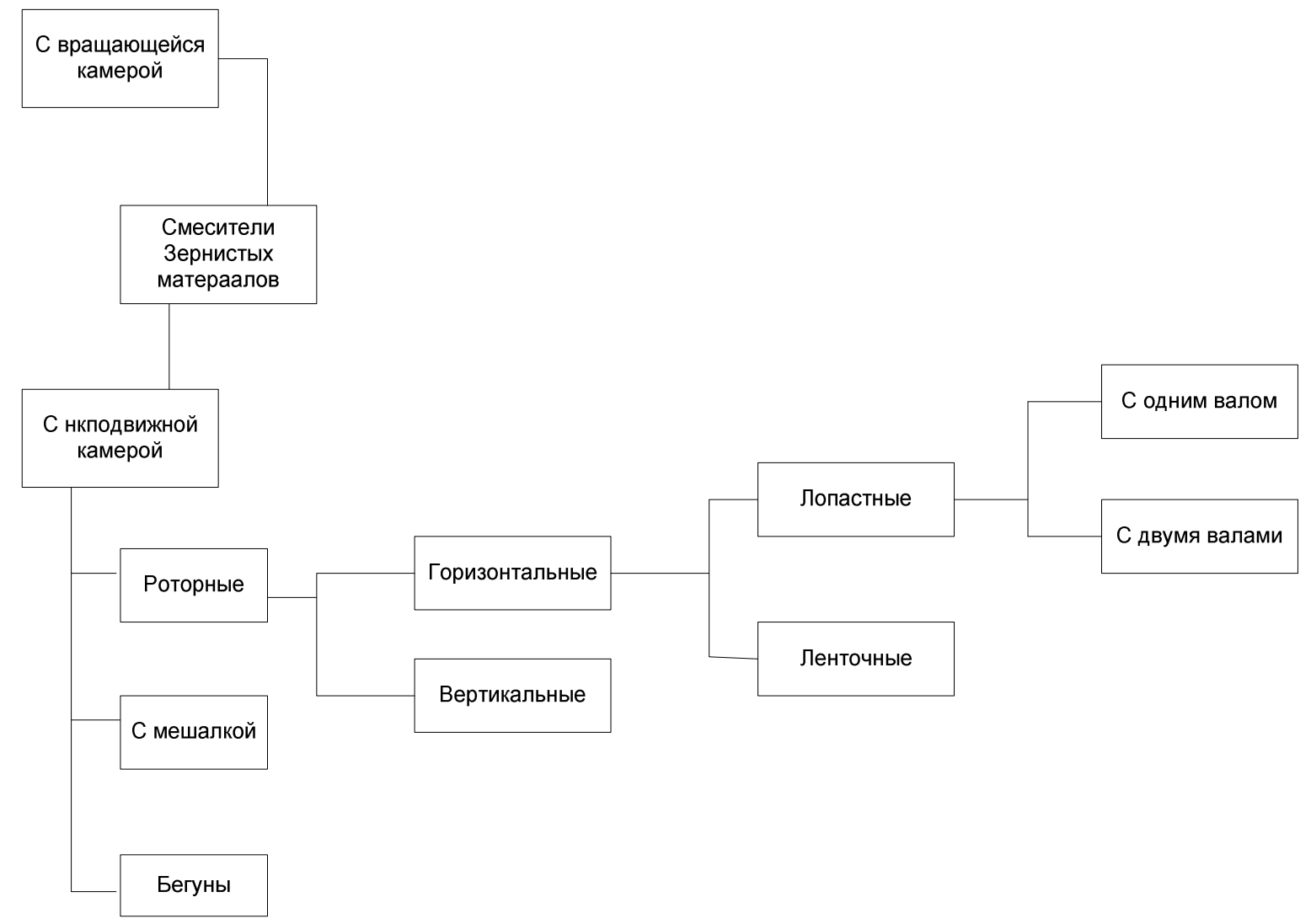

Рисунок 1 - Классификация смесетелей

\section{3. Система имитационного моделирования програмы AnyLogic}

В работе для Имитационного моделирования технологических процессов управление смешивания используем среда AnyLogic [6 - 14]. Система имитационного моделирования AnyLogic позволяет расширять созданные модели с помощью языка Java, которая позволяет достаточно глубоко и точно учитывать конкретные особенности динамики объекта автоматизации. Среда AnyLogic позволяет не только проводить имитационный прогон технологического процесса, но и проводить анимацию для наблюдения его хода в реальном времени, что немаловажно при решении задач оптимизации управления. 
Имитационное моделирование - это метод исследования, при котором изучаемая система заменяется моделью с достаточной точностью описывающей реальную систему и с ней проводятся эксперименты с целью получения информации об этой системе.

AnyLogic ${ }^{\mathrm{TM}}$ - инструмент имитационного моделирования новейшего поколения. Он основан на результатах, полученных в теории моделирования и в информационных технологиях за последнее десятилетие.

Уникальность AnyLogic ${ }^{\mathrm{TM}}$ состоит в его способности эффективно решать задачи моделирования любого масштаба и уровня абстракции, в том числе для разнородных систем в их взаимосвязи.

\section{4. Операционный уровень моделирования}

AnyLogic имеет развитый базовый язык дискретного и смешанного дискретно/непрерывного моделирования, на основе которого построены решения для конкретных областей: библиотека Enterprise Library, а также Material Flow Library (потоки материалов) и Healthcare Library (работа медицинских учреждений). Реализация стандартных объектов открыта для пользователя, их функциональность может быть как угодно расширена, вплоть до создания собственных библиотек.

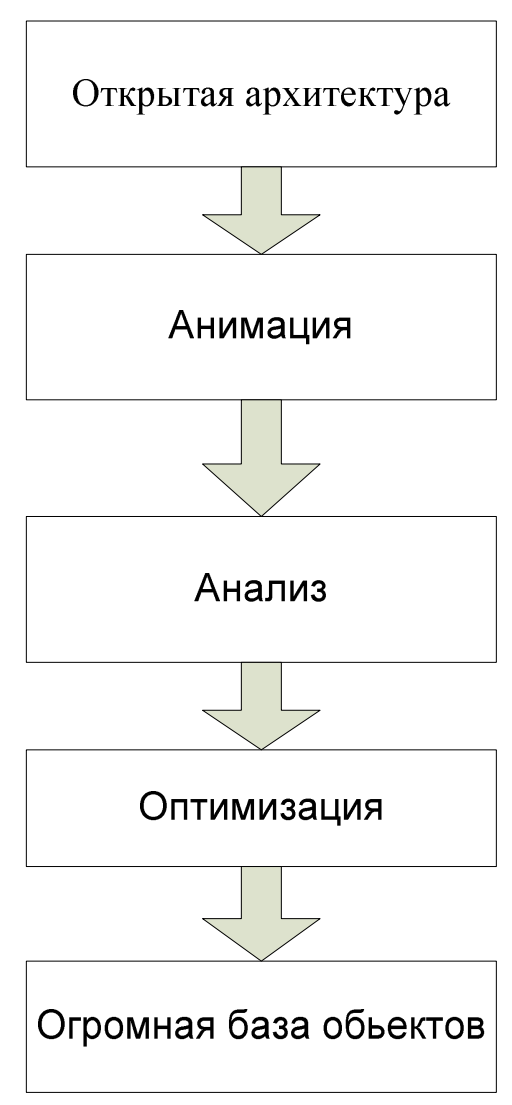

Рисунок 2 - Возможности AnyLogic 


\section{5. Моделирование процесса приготовления многокомпонентных смесей в горизонтальном барабанном смесителе}

Математическая модель и формирование задачи оптимизации процесса смешивания материалов в смесителе непрерывного действия для горизонтального бараьанного смесителя.

Математическое описание процесса приготовления многокомпонентных смесей в горизонтальном барабанном смесителе может быть записано следующим образом:

$c_{0}(t)=\beta_{1} \cdot e^{\alpha . t}+\beta_{2} \cdot e^{-\alpha . t}+\alpha / 2$,

где $\alpha=4 . \overline{D_{R}}=0,2 . R_{\ni}^{2}$

Неизвестные коэффициенты ${ }^{{ }_{1}}{ }_{\text {и }} \beta_{2}$

После решения обычной системы алгебраических уравнений. После этого устанавливается окончательная форма оптимальной нормировочной ПРВП.

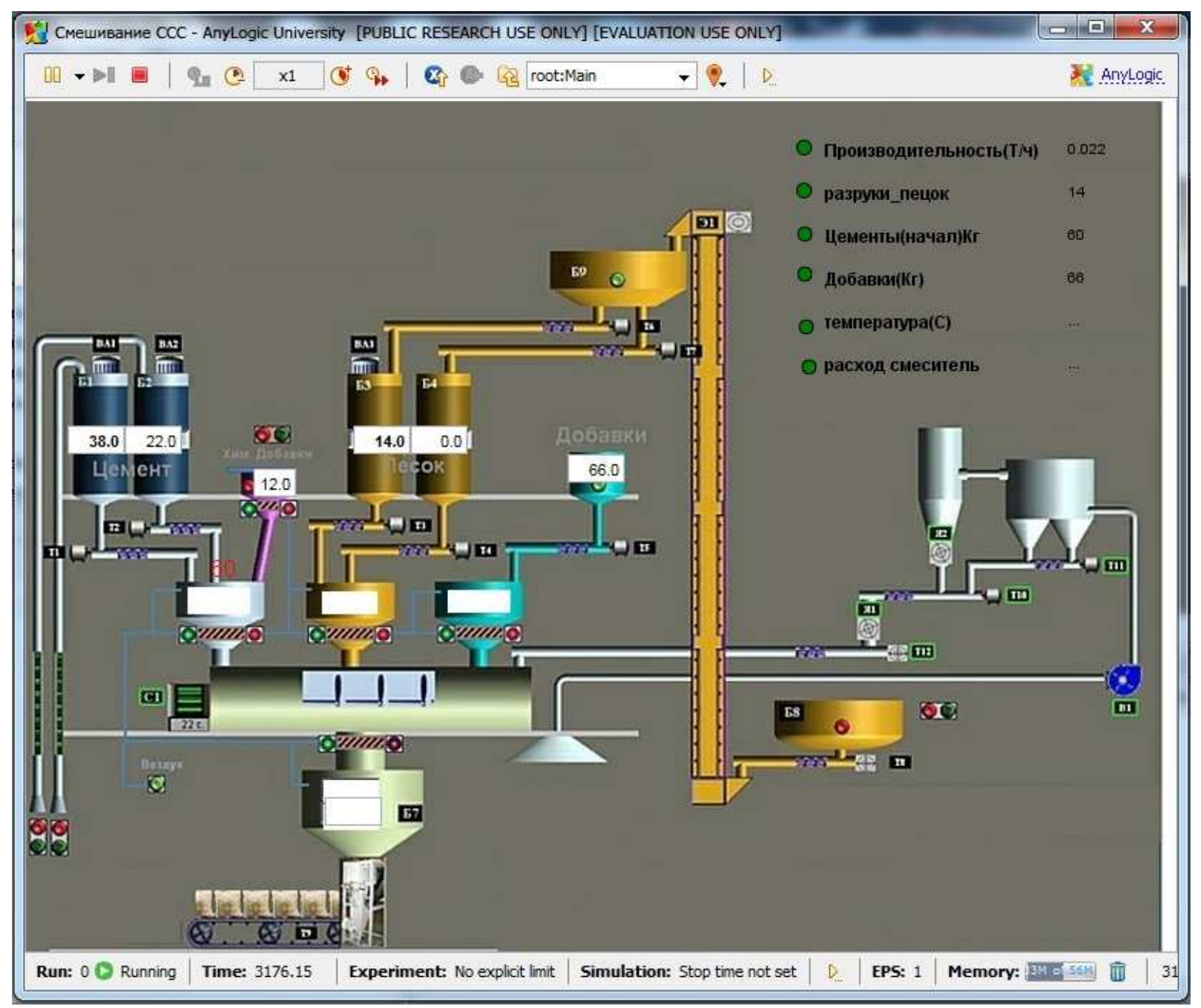

Рисунок 3 - Мнемоскема АC ССC 


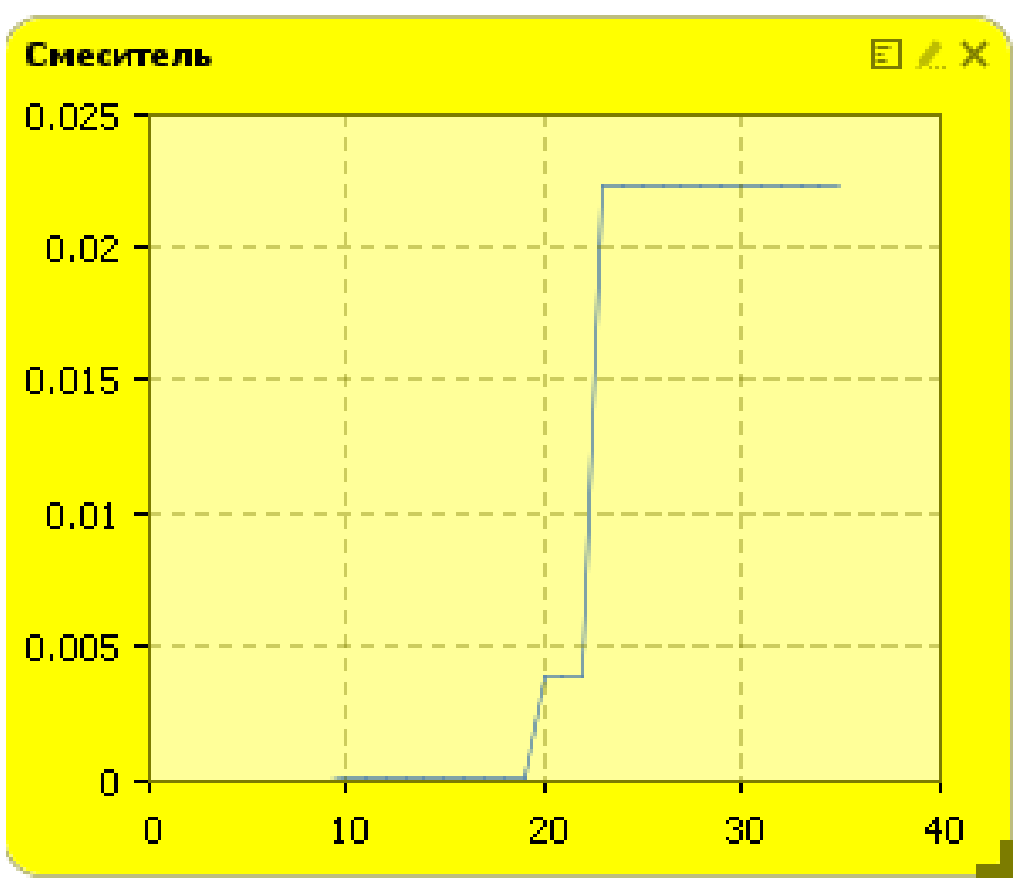

\section{Рисунок 4 - Приготовление многокомпонентных смесей}

Этим фактом обусловлен выбор подходов, которые будут использованы для описания процесса получения многокомпонентных смесей, хотя имеются некоторые серьезные отличия, связанные с усложнением механизма сегрегации компонентов. Исследования характера движения компонентов в циркуляционных смесителях непрерывного действия показывают, что при разбиении конструкции на участки небольшой длины можно считать каждый такой участок смесителем периодического действия со временем смешивания, соответствующем времени пребывания материала на этом участке. Как следствие, рассмотрение вопроса, связанного с моделированием процесса в поперечном сечении смесителя приобретает большое прикладное значение и для случая исследования смесителей непрерывного действия. Для трехкомпонентной смеси необходимо рассмотреть следующие двухкомпонентные сочетания: $\mathrm{A}+\mathrm{B}, \mathrm{A}+\mathrm{C}$, $\mathrm{B}+\mathrm{C}$.

\section{6. Заключение}

Практические результаты исследований процессов непрерывного смешивания материалов на промышленных предприятиях по производству сухих смесей заключаются в том, что они являются базой для научно обоснованного выбора и настройки структур систем оптимального управления компонентов непрерывного действия, позволяющих решать задачи повышения точности смешивания.

Разработана математическая модель цирукуляции материалов в смесителе при установившемся режиме работы, получены аналитические зависимости для определения моделирования процесса приготовления многокомпонентных смесей в горизонтальный барабанный смеситель. 


\section{Список информационных источников}

[1] Вэй Пьо Аунг, Остроух А.В. АСУТП производства сухих строительных смесей // Автоматизация и управление в технических системах. - 2013. - № 1(3). - С. 26-29.

[2] Вэй Пьо Аунг, Остроух А.В. Автоматизированная система управления технологическим процессом производства сухих строительных смесей // Автоматизация и управление в технических системах. - 2013. - № 2(4). - С. 76-82.

[3] Вэй Пьо Аунг. Краткий обзор современного состояния развития производства сухих строительных смесей // Автоматизация и управление в технических системах. - 2012. - № 1. - С. 11-16.

[4] Вэй Пьо Аунг. Оборудование для производства сухих строительных смесей // Автоматизация и управление в технических системах. - 2013. - № 4.1. - С. 4-7. DOI: $10.12731 / 2306-1561-2013-4-2$.

[5] Остроух А.В. Обзор современного состояния развития автоматизации производства сухих строительных смесей / А.В. Остроух, Вэй Пьо Аунг, Мьо Лин Аунг, М.И. Исмоилов // В мире научных открытий. Серия «Проблемы науки и образования». - 2012. - №12. - С.12-19.

[6] Остроух А.В. Основы построения систем искусственного интеллекта для промышленных и строительных предприятий: монография / А.В. Остроух. - М.: OОО «Техполиграфцентр», 2008. - 280 с. - ISBN 978-5-94385-033-2.

[7] Остроух А.В. Информационные технологии в научной и производственной деятельности / [ред. А.В. Остроух] - М: ООО "Техполиграфцентр", 2011. - 240 с. ISBN 978-5-94385-056-1.

[8] Остроух А.В. Ввод и обработка цифровой информации: учебник для нач. проф. образования / А.В. Остроух. - М.: Издательский центр «Академия», 2012. - 288 с. - ISBN 978-5-7695-9457-1.

[9] Остроух А.В. Исследование начального периода моделирования на точность среднеинтегральной оценки имитационных моделей / A.В. Остроух, А.А. Солнцев, Н.В. Солдатов, К.А. Новицкий, П.С. Якунин // Вестник МАДИ. - 2010. Вып. 2(21). - С. 61-65.

[10] Остроух А.В. Системы искусственного интеллекта в промышленности, робототехнике и транспортном комплексе: монография / А.В. Остроух Красноярск: Научно-инновационный центр, 2013. - 326 с. - ISBN 978-5-906314$10-9$.

[11] Остроух А.В. Автоматизация и моделирование работы предприятий по строительству промышленных объектов: дис. ... д-ра техн. наук: 05.13.06: защищена 07.04.09: утв. 19.06.09. - М., 2009. - 357 с.

[12] Остроух А.В. Автоматизация и моделирование работы предприятий по строительству промышленных объектов: автореф. дис. ... д-ра техн. наук: 05.13.06. - М., 2009. - 43 c.

[13] Остроух А.В. Автоматизация управления производством. Повышение эффективности автоматизированных аналитических систем предприятий автомобильной промышленности / А.В. Остроух, Э.А. Чернов, Нгуен Дык Тхань. Saarbrucken, Germany: LAP LAMBERT Academic Publishing, 2013. - 285 p. - ISBN 978-3-659-34762-7.

[14] Остроух А.В. Автоматизация управления строительным предприятием / А.В. Остроух // Приборы и системы. Управление, контроль, диагностика. - М.: «Научтехлитиздат», 2004. - №8. - С. 58-61. 